\title{
El comercio intra latinoaméricano en los años noventa y su base analítica ${ }^{1}$
}

\section{Ricardo Ffrench-Davis}

El autor menciona cinco puntos relacionados con el comercio de bienes y servicios que proporcionan las bases analíticas para fundamentar acuerdos de integración regionales con regímenes de importación preferenciales. Estos comprenden graves restricciones impuestas al desarrollo de la producción y al comercio de bienes y servicios. Sugiere fórmulas superar parcialmente estos obstáculos a través de la integración regional como arma estratégica. Analiza cifras del comercio intrarregional y la calidad de las exportaciones, señalando como fuentes de su expansión la geografía, la relajación de la restricción externa dominante, la apreciación del tipo de cambio real y los acuerdos comerciales subregionales. En cuanto a la composición del comercio recíproco y la intensidad tecnológica, estima que el conercio entre los paises en desarrollo se caracteriza por concentrarse en productos que son más intensivos en tecnología que las exportaciones a los países industrializados. Finaliza señalando algunos problemas que podría plantear el comercio en el futturo.

\section{Base analítica para los acuerdos comerciales preferentes}

En América Latina se han emprendido profundas reformas comerciales como parte de un amplio proceso de cambios en que la competitividad internacional y las exportaciones juegan un papel protagónico. La mayoría de los países procuran alcanzar un desarrollo liderado por las exportaciones. Sin

\footnotetext{
${ }^{1}$ Agradezco los comentarios recibidos con ocasión de la conferencia pronunciada en el Diplomado "Los procesos de Integración y la Cooperación Regional", de la Catedra Internacional Andrés Bello, en el Instituto de Estudios Internacionales. Serä publiçado como un capítulo de R. Ffrench-Davis, Macroeconomía, comercio y finanzas: para reformar las reformas, McGraw-Hill, Santiago.
} 
embargo, contrariamente a lo que sucedió en los países del este de Asia, el principal mecanismo de la reforma comercial ha sido la liberalización relativamente indiscriminada y acelerada de las importaciones (véase FfrenchDavis, 1999, cap. III; y CEPAL, 1998, cap. V). La mayoría de los países latinoamericanos introdujeron reformas que podrían considerarse drásticas y abruptas. En general, la protección arancelaria vigente en la actualidad difiere notoriamente de los niveles anteriores a la reforma, y la dispersión de las tasas de protección efectiva se ha reducido considerablemente. Por ejemplo, el promedio simple del arancel externo se rebajó desde $45 \%$ a mediados de los ochenta, a $13 \%$ actualmente (ver el gráfico 1). Sin embargo, hasta ahora, ningún país ha adoptado una tasa arancelaria cero. Estas tendencias regionales de la política comercial se han complementado con la aplicación de convenios bilaterales o multilaterales de libre comercio, que abarcan una extensa gama de productos. El hecho de que los aranceles sean distintos de cero pero tengan niveles moderados, da lugar a preferencias arancelarias recíprocas pero a una desviación de comercio notablemente más limitada que en los programas anteriores de integración comercial.

Los escritos tradicionales sobre los costos y beneficios de la integración económica se centran en las preferencias arancelarias dentro de un marco de equilibrio competitivo óptimo. Convencionalmente, se trabaja con el supuesto de que la única desviación respecto de este equilibrio es la presencia de restricciones a las importaciones. En este marco, la integración sólo es beneficiosa si entraña un avance hacia el libre comercio. En otras palabras, si los efectos de la creación de comercio (el desplazamiento hacia fuentes de abastecimiento más económicas) son superiores a aquellos de la desviación del comercio (desplazamiento hacia fuentes de abastecimiento más costosas). No obstante, lo esencial es la forma como se miden los costos; de acuerdo con el sistema convencional, éstos se cuantifican a los precios de mercado netos de aranceles, ignorando los costos de transición y la presencia de mercados incompletos, así como la capacidad de adquirir competitividad. El supuesto lleva a la obvia conclusión de que la política nacional óptima, en vez de cualquier integración regional, es la liberalización general unilateral.

Entonces, ¿cuál es la razón por la que tantos países quieren participar en procesos de integración, aún en estos tiempos en que está de moda el libre comercio unilateral? La integración regional se sustenta en consideraciones estratégicas originadas en la existencia de mercados incompletos e imperfec- 
tos, internos o externos, que ponen trabas a la captación y difusión de las ganancias de eficiencia y al desarrollo de nuevos patrones productivos con niveles progresivamente más elevados de conocimiento y valor agregado. Los cinco puntos que se mencionan a continuación están relacionados con el comercio de bienes y servicios. Ellos proporcionan las bases analíticas para fundamentar acuerdos de integración regionales con regímenes de importación preferenciales. Asumimos que la integración regional tiene lugar en un marco definido de regionalismo abierto, con aranceles externos «moderados».

a) Primero, los mercados mundiales no son totalmente abiertos y estables. Sin embargo, son amplios, han crecido $50 \%$ más rápido que el PIB en los últimos cincuenta años, alcanzando un quinto del PIB mundial. Sin embargo, las exportaciones de los países de América Latina (PALs) se concentran en recursos naturales primarios y semielaborados. En consecuencia, estén participando o no en acuerdos comerciales preferenciales (ACPs), los mercados mundiales han sido y seguirán siendo decisivos para las exportaciones tradicionales de los PAL.s; en los mercados de esos rubros predomina la inestabilidad, pero se relaciona más bien con los precios que con el acceso (de volumen). No obstante, en el caso de muchos productos no tradicionales (incluyendo recursos naturales no tradicionales), el acceso a los mercados es más limitado e inestable. Es en estos productos en que los ACPs adquieren especial importancia.

b) Segundo, en vista de las distorsiones en el acceso a los mercados mundiales, para un país emergente es más difícil aprovechar las economías de escala y de especialización. El mejoramiento del acceso a los mercados externos ayuda a aprovechar esas economías y, de hecho, este logro ha sido la meta principal de los responsables de las políticas y una fuerza estimulante para los ACPs regionales.

En consecuencia, frente a economías de escala, lo que de otra forma podría ser una desviación de comercio ineficiente, puede convertirse en una desviación de comercio reductora de costos e incrementadora del bienestar. ${ }^{2}$

c) Tercero, los mercados internos de factores son incompletos o distorsionados. La capacitación de la mano de obra, la tecnología y el capital de largo

\footnotetext{
${ }^{2}$ La geometría de las economías de escala y sus implicancias para el signo de bienestar de la desviación de comercio se tratan en Corden (1972) y se expanden a otras situaciones en Ffrench-Davis (1980). Un buen recuento sobre evaluación de ACPs se presenta en Winters (1998).
} 
plazo escasean, y sus respectivos mercados son inexistentes o incipientes en los PALs. Estas fallas del mercado son más importantes para las exportaciones no tradicionales de productos diferenciados, ya se trate de recursos naturales, manufacturas o servicios exportables. Si se mejora el acceso de estos productos a los mercados externos, puede fortalecerse la eficacia de los esfuerzos para completar mercados y diluir su segmentación.

d) Cuarto, en los países en desarrollo, la infraestructura, el financiamiento del comercio y el conocimiento de los mercados (canales de comercialización, transporte organizado, normas, etc.) tienen frecuentemente un sesgo contra el comercio intrarregional. Generalmente, todos estos «factores» del comercio se han desarrollado más en el caso de negocios con el «centro», mientras que son inexistentes o más rudimentarios en el caso del comercio entre PALs vecinos. Esta es una de las variables importantes que explican por qué en los países latinoamericanos el comercio intrarregional ha sido menor a lo que podría indicar la gravitación de la geografía.

e) Quinto, en las economías que están reformando la política comercial, el abandono de la protección excesiva y arbitraria para los sustitutos de importaciones y los insumos de exportables, tiende a producir importantes costos de transición. Estos aumentan si la reforma es abrupta y si se revalua el tipo de cambio durante el proceso, como ha sido el caso de la mayoría de los países latinoamericanos en los años noventa.

En los años sesenta y setenta, los países del este de Asia minimizaron los costos de transición mediante una estrategia basada en la apertura de sus exportaciones hacia la economía mundial (véase Ffrench-Davis, 1999, cap. III). Así, países como Japón, la República de Corea y Taiwán, en sus procesos de apertura pusieron mayor énfasis en la promoción de exportaciones que en la liberalización de importaciones, generando de este modo un balance de impulsos netos positivos a la producción interna de comerciables (estimulando el uso de la capacidad, y la inversión para aumentar ese potencial). En vista de que los países latinoamericanos optaron por una reforma liderada por las importaciones, un proceso paralelo de acuerdos comerciales preferenciales se torna más atractivo, con el fin de aumentar la eficiencia de la transformación productiva (CEPAL, 1998). En realidad, estos acuerdos agregan un elemento compensatorio a la liberalización unilateral de las importaciones (más aún si el tipo de cambio se ha revaluado en el proceso), estimulando exportaciones recíprocas en paralelo con las importaciones recíprocas. En conse- 
cuencia, en presencia de ACPs, los impulsos positivos y negativos a la actividad económica y a la inversión exhiben un mejor balance que en los casos de liberalización unilateral pura de las importaciones.

Estos cinco puntos comprenden graves restricciones impuestas al desarrollo de la producción y al comercio de bienes y servicios, intensivos en conocimiento y aprendizaje difundibles, factores que ahora se reconocen como componentes claves del proceso de crecimiento. La integración regional puede ser un arma estratégica para superar parcialmente estos obstáculos (Devlin y Ffrench-Davis, 1998):

-Expandiendo el tamaño del mercado para facilitar una mayor especialización e industrialización, a través de las economías de escala y de la posibilidad de explotar economías asociadas con la aglomeración de la actividad productiva.

-Fortaleciendo el impulso de la competencia, al ampliar el mercado con acceso recíproco estable, e intensificando la especificidad de los flujos de información, todos los cuales, a su vez, estimulan nuevas inversiones internas y permiten atraer inversión extranjera directa (IED) eficiente.

Creando acceso más seguro a los mercados subregionales y aprovechando la familiaridad con los países vecinos, se acelera el surgimiento de nuevos productores y comercializadores de exportaciones no tradicionales. En efecto, la curva de aprendizaje asociada a la experiencia de intercambio intrarregional puede servir de plataforma para nuevas exportaciones internacionales, adquiriendo entonces ventajas comparativas dinámicas, en la ruta de su convergencia con la productividad de los países industrializados. La mayor competitividad internacional que se espera de la integración regional debiera contribuir a que los países se preparen mejor para la globalización y posteriores avances en la liberalización multilateral.

El examen del perfil de las exportaciones intrarregionales permite apreciar la dimensión estratégica del proceso de integración. Las exportaciones intra y extrarregionales de América Latina muestran marcadas diferencias en cuanto a su estructura de productos y de contenido tecnológico, captando las manufacturas una participación mucho mayor en el comercio intrarregional (véanse los cuadros 1 y 2 ). 


\section{El comercio intrarregional y la calidad de las exportaciones}

El valor de las exportaciones intrarregionales más que se triplicó entre 1990 y 1997. Al principio, se trató más que nada de un repunte a partir de la caída profunda que había registrado en los años ochenta. Sin embargo, ya en 1992 se registró una cifra récord, con un aumento adicional en 1993-94. Posteriormente, debido al "efecto tequila", se redujo la participación de las exportaciones intrarregionales, en especial aquellas dirigidas a los mercados de Argentina y México, seguido por una recuperación en 1997. No obstante, el MERCOSUR registra un aumento persistente del comercio recíproco entre países asociados, con un incremento de su participación desde $9 \%$ en 1990 a 24\% en 1997.

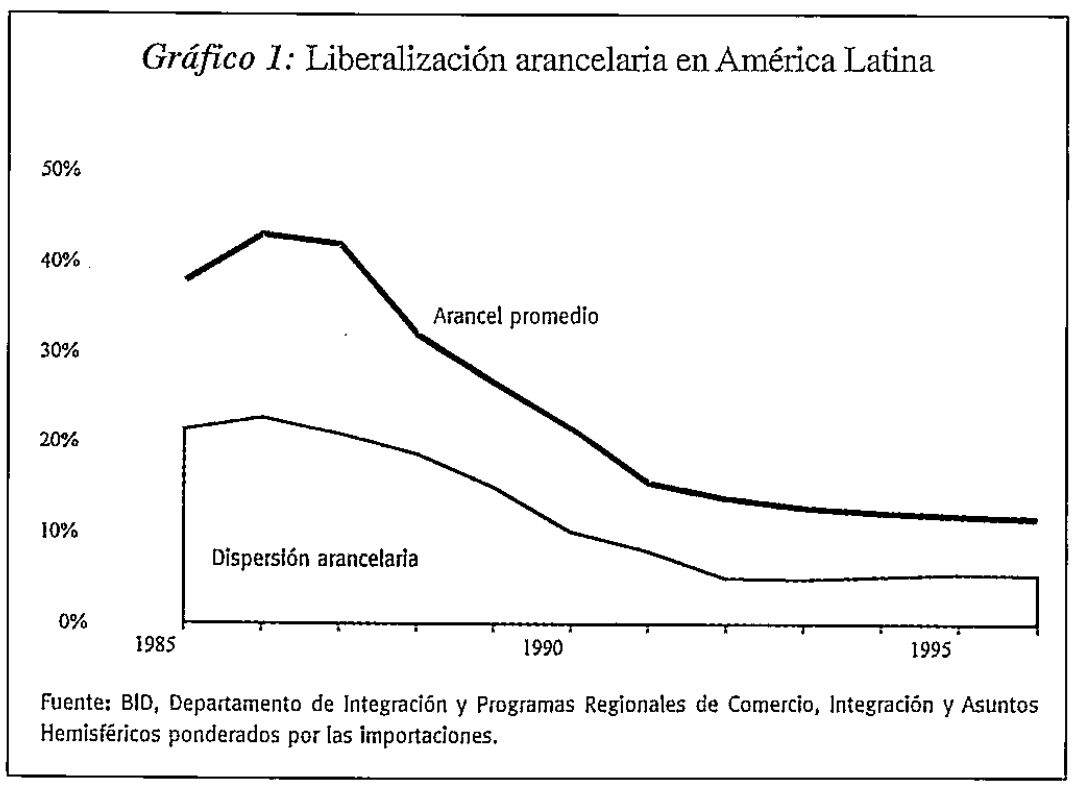

Es interesante hacer una comparación entre el crecimiento del PIB, el total de las exportaciones y las exportaciones intrarregionales (todos en términos reales). El PIB de América Latina creció 22\% entre 1990 y 1996, mientras que el total de las exportaciones aumentó $59 \%$. Dentro de éstas, las exportaciones intrarregionales se expandieron $160 \%$, mientras que hacia mercados extrarregionales aumentaron 44\%; es decir, más rápidamente que el comercio mundial, con una elasticidad bruta de $2 \%$ respecto del PIB. Esta 
información sustenta la hipótesis del regionalismo abierto, con un rápido crecimiento del comercio hacia todos los mercados, pero con una proporción en alza de aquel destinado a los socios comerciales.

\section{Las fuentes de la expansión del comercio intrarregional}

Algunos factores que influyen significativamente en la tendencia observada son: la geografía, la reducción de la restricción externa dominante al inicio de los noventa, una apreciación del tipo de cambio real y la implementación de los ACPs.

- Geografía. Aquellas áreas contiguas, densas en población y capital, generalmente tienden a interactuar en forma natural, y a comerciar relativamente con más intensidad y mayor especialización. Entre los factores económicos imputables están las externalidades asociadas a localización y aglomeraciôn. La similitud de niveles de ingreso, culturales, gustos e idiomas, como sucede en América Latina, y la subsistencia de diferenciales en el costo de transporte entre países vecinos y no vecinos pueden aumentar más aún esta tendencia. En concordancia con este criterio, parecieran existir en América Latina extensas áreas geográficas naturales de integración económica: en el Cono Sur, Venezuela-Colombia-Ecuador, Centroamérica y Norteamérica para México. De hecho, el auge del comercio intrarregional ha sido mayoritariamente entre países vecinos de la región (véase el gráfico 2 y Devlin y Ffrench-Davis, 1998). El factor geográfico todavía gravita en forma preponderante.

- Relajación de la restricción externa dominante. La disminución de las tasas de interés mundiales, el alivio de la deuda y el regreso de los flujos externos de capital en los noventa (véase Ffrench-Davis, 1999, cap. V; y CEPAL, 1998, cap. (X) han aumentado en forma importante la capacidad para importar de la región, con la consiguiente reactivación de la actividad económica. En vista de que las importaciones intrarregionales son idénticas a las exportaciones intrarregionales, el auge generalizado de las importaciones se ha reflejado en un notorio crecimiento de las exportaciones intrarregionales.

- Apreciación del tipo de cambio real. La conducta del tipo de cambio de los PALs también ha influido en el comportamiento del comercio externo de la región. La liberalización simultánea de la cuenta de capital en muchos países, unida a un repunte de la oferta de capital extranjero y a la utilización de anclas cambiarias en apoyo de los programas de estabilización, contribu- 
yó a que se produjeran apreciaciones monetarias reales en un número importante de países (justo cuando lo necesario para facilitar un crecimiento liderado por las exportaciones era una depreciación real). Sin embargo, en vista de que en los años noventa la apreciación real del tipo de cambio con respecto al resto del mundo ha sido simultánea en un número significativo de los países de América Latina, naturalmente no hay "apreciación" entre ellos. Por consiguiente, los efectos negativos de la apreciación sobre las exportaciones han sido relativamente más potentes en el mercado extrarregional, estimulando a los exportadores a redirigir sus ventas hacia los mercados regionales.

- Acuerdos comerciales subregionales. La explosión, en los noventa, de acuerdos comerciales subregionales y bilaterales ha estimulado el comercio intrarregional a través de varios efectos que se refuerzan recíprocamente, como por ejemplo:

- Las preferencias comerciales son parte integral de los acuerdos de integración y suministran incentivos importantes para el comercio intrarregional. El nivel absoluto de la preferencia en el tiempo dependerá de la evolución de las tasas arancelarias externas, dado que los aranceles internos de los ACPs han tendido rápidamente a su desaparición.

- Un flujo acrecentado de información y atención pública hacia las oportunidades comerciales en un mercado adyacente. El estímulo provisto por los ACPs ha sido asistido también por la liberalización comercial unilateral, que ha constituido un factor clave para exponer las oportunidades naturales de mercado para exportaciones a países vecinos, ocultas hasta los años ochenta tras una fuerte protección nacional. Sin embargo, es importante señalar que la liberalización unilateral del comercio a fines de los años ochenta y comienzos de los noventa, erosionó progresivamente muchas de las preferencias excesivas de los antiguos acuerdos comerciales en la región; no obstante, predomina el efecto de la reducción del nivel de los aranceles internos a los que ha estado afecto el intercambio recíproco.

- Los ACPs han dado al sector privado un acceso recíproco y legalmente obligatorio al mercado, que ha reducido (aunque no eliminado) los riesgos de reposición de barreras en los mercados asociados.

- Un acuerdo preferencial puede indicar el compromiso constante de las autoridades de gobierno con la expansión comercial. En acuerdos tales como el MERCOSUR, la liberalización comercial subregional está acompañada por un compromiso adicional que involucra un amplio mensaje político, 
gestado al más alto nivel oficial, de promover una profunda integración económica y cooperación política entre los países miembros. Esto, a su vez, aumenta la confianza del sector privado para que se materialicen inversiones productivas de naturaleza irreversible.

\section{La composición del comercio recíproco y la intensidad tecnológica}

El perfil de las exportaciones intrarregionales pone de manifiesto una modificación sustancial en la composición de las exportaciones de los PALs: el predominio de las exportaciones primarias fue parcialmente reemplazado por las manufacturas, que actualmente representan la mitad del comercio intrarregional. Este incremento notable de las exportaciones manufacturadas corresponde especialmente a las industrias nuevas, incluidas tanto actipidades intensivas en mano de obra como en capital.

Las economías latinoamericanas ofrecen importantes y dinámicos mercados a las ventas de manufacturas de varios países latinoamericanos (CEPAL, 1998, cap.II). En el caso de Chile, Colombia y Ecuador, éste es lejos el mercado principal de destino, ya sea de industrias tradicionales, insumos básicos o industrias nuevas. En el caso de Argentina, Paraguay y Uruguay, esta concentración no es tan marcada; el mercado de las industrias tradicionales de estos países es bastante diversificado y, en Argentina, también lo es el de la industria de insumos básicos. Sin embargo, América Latina sigue siendo prácticamente el único destino de las exportaciones de las industrias nuevas de estos países. Lo mismo sucede con su respectivo mercado subregional, en el caso de las nuevas industrias de Costa Rica y Guatemala. En cuanto a Brasil, el destino de sus exportaciones de manufacturas está muy diversificado; lọ Estados Unidos siguen siendo el principal comprador de sus productos tradicionales, seguido de Europa; en lo que respecta a los insumos básicos, otras regiones en desarrollo han desplazado a América Latina como destino principal, aunque en el caso de las industrias nuevas, la región es también el mercado más importante de Brasil. La excepción es México, donde el mercado regional tiene menos importancia relativa que los Estados Unidos. Es muy pertinente reiterar que el comercio fronterizo (con países vecinos) representa la mayor parte del comercio intrarregional, lo que prueba una vez más la importancia de la situación geográfica.

Los efectos dinámicos derivados del aprendizaje de tecnología dan im- 
pulso al desarrollo basado en la competitividad internacional creciente y sostenida. Las estrategias para mejorar las vinculaciones internacionales basadas en el desarrollo productivo ponen de relieve el papel que desempeña el comercio en el proceso de estimulación de las actividades que utilizan un alto coeficiente de conocimientos y tecnología.

En este sentido, generalmente se piensa que el comercio entre los países en desarrollo se caracteriza por concentrarse en productos que son más intensivos en tecnología que las exportaciones a los países industrializados. ${ }^{3} \mathrm{El}$ cuadro 2 contiene información sobre los PALs, la que confirma la validez de esta hipótesis. Muestra en qué medida las exportaciones intrarregionales tienen un contenido mayor de tecnología, en especial avanzando de un nivel bajo a uno mediano, que se prestan mejor a la etapa semi-industrializada en que se encuentra América Latina. La misma conclusión se desprende de un estudio de la CEPAL (1994, cap. II.A) que combina estadísticas sobre el comercio exterior y la producción. Las cifras revelan que los productos que exhiben una participación relativamente elevada de su demanda en el mercado regional, tienen características tecnológicas más avanzadas que las exportaciones que se canalizan hacia los mercados extrarregionales o internos. En consecuencia, tienden a aportar más externalidades a las economías internas.

\footnotetext{
${ }^{3}$ Otro enfoque, estático y basado en sôlo dos factores, considera que el comercio de los países en desarrollo tiende a ser intensivo en capital, en oposición al comercio con naciones industrializadas. Esta línea de pensamiento presupone que para los paises en desarrollo es más conveniente el comercio con países ricos.
} 
Ricardo Ffrench Davis / EI comercio intra latinoaméricano en los años noventa y su base analítica.

\section{Gráfico 2: Comercio intraregional y fronterizo}
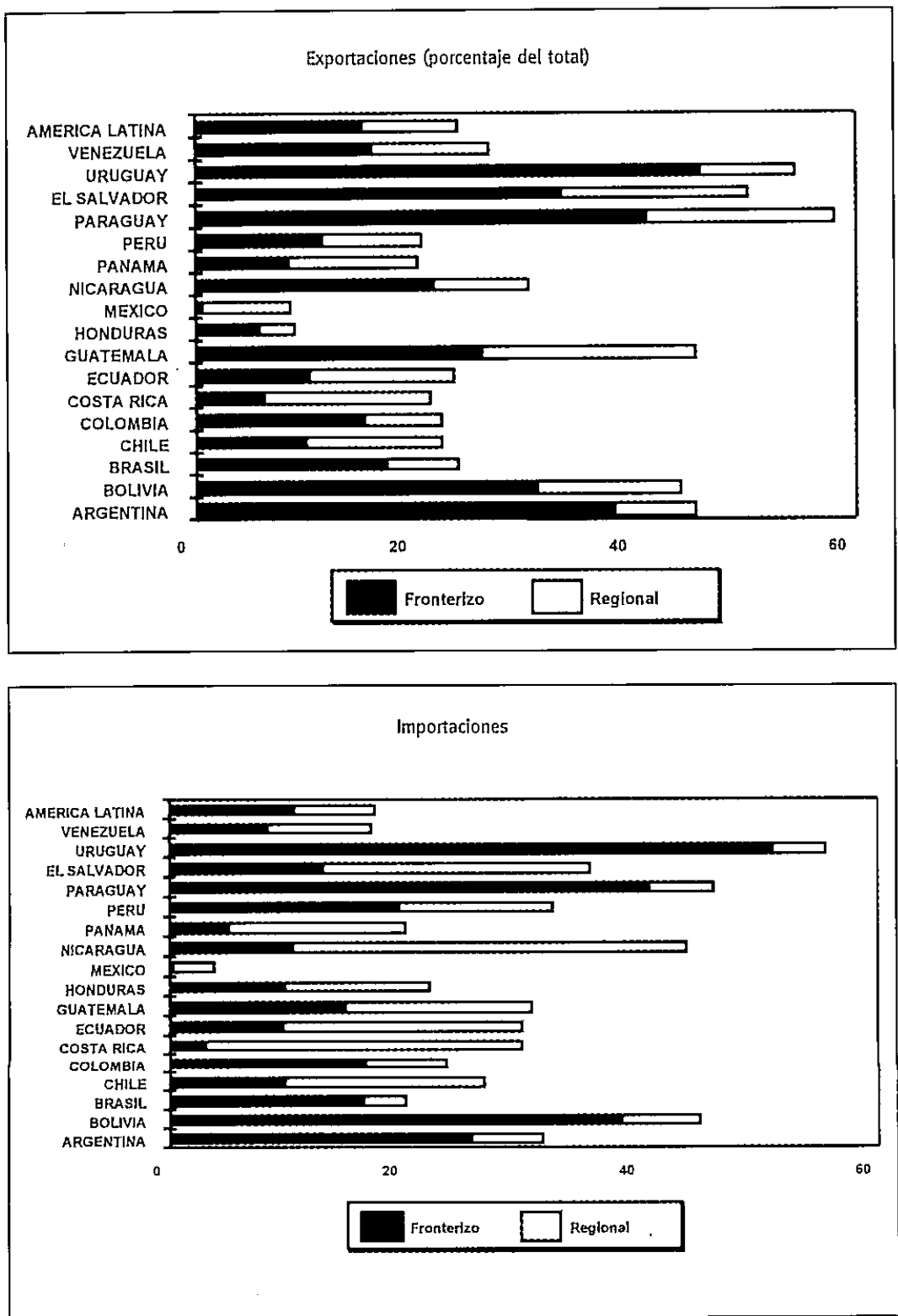

Fuente: BID, Departamento de Integración y Programas Regionales, División de Integración, Comercio y Asuntos Hemisféricos. Nota: Los países que se incluyen son aquellos que comparten fronteras y que tienen información disponible. El comercio fronterizo mexicano no incluye el comercio con Estados Unidos. 
Las investigaciones publicadas por la CEPAL (1994) permiten llegar a tres conclusiones, a saber:

i) La producción de bienes que dependen en mayor medida del comercio intrarregional tiene rasgos tecnológicos más sofisticados. Estos productos corresponden generalmente a los sectores de productos químicos, maquinaria no eléctrica y equipo de transporte. Asimismo, se trata de sectores en que la demanda internacional tiende a ser más dinámica. Sus precios suelen ser más estables y evolucionar de manera más positiva en el largo plazo que los precios de las exportaciones tradicionales.

ii) Los sectores que muestran un fuerte sesgo hacia la región también tienden, a veces con un rezago, a orientarse hacia los mercados extrarregionales, lo que sugiere que el fomento del comercio intrarregional complementa la promoción de las exportaciones extrarregionales.

iii) Estos son los mismos sectores en que la región tiene marcada dependencia de las importaciones intermedias extrarregionales; en consecuencia, el comercio intrarregional se beneficia del acceso a insumos y equipos que pueden importar de terceros países. Así pues, el relajamiento de las restricciones excesivas a las importaciones ha contribuido a estimular y mejorar las exportaciones.

En síntesis, las particulares características del comercio intrarregional, unidas a la proximidad geográfica y a la similitud de los niveles de desarrollo, complementan las vinculaciones de los países latinoamericanos con la economía mundial y ofrecen un marco dinámico de aprendizaje tecnológico, que conduce a una mayor competitividad internacional y a una modalidad de especialización más diversificada y equilibrada.

Más aún, dada la coyuntura macro-económica a comienzos de los noventa, el comercio recíproco hizo una contribución tipo neokeynesiana a las economías de los PALs. En efecto, el incentivo a las exportaciones intrarregionales ha aumentado la demanda de recursos internos y de inversión, lo que es beneficioso para el crecimiento y la eficiencia, en el marco de economías que operan bajo la frontera productiva y que llevan a cabo la liberalización de las importaciones. No hay duda alguna de que la reactivación de las economías latinoamericanas ha estado vinculada con el acceso renovado al financiamiento externo (CEPAL, 1998, cap.XI). Sin embargo, el auge del comercio intrarregional ha contribuido a la contrapartida real del proceso de ajuste en curso. Los aranceles preferenciales, la eliminación de las restricciones recíprocas a las importaciones, y la creación de cauces adicionales para la salida de la pro- 
ducción interna (armonización de normas, transporte, mejoramiento de la infraestructura, canales de comercialización, inversiones recíprocas, etc.), han contribuido a aumentar la tasa de uso de los recursos y a estimular la inversión productiva.

\section{Problemas que podría plantear el comercio en el futuro}

La integración económica regional ofrece importantes beneficios económicos, a la vez que políticos, sociales y culturales a América Latina. Sin embargo, la transición puede acarrear grandes costos e incertidumbres.

En los primeros años del decenio la transición ha sido fácil. La integración se produjo en un ambiente de reactivación económica y luego de un sobreajuste recesivo de las importaciones intrarregionales. De esta manera, había margen para un amplio incremento no conflictivo del comercio recíproco. La región aprovechó bien esta oportunidad.

En la actualidad, la región está enfrentando un nuevo ajuste, asociado a la crisis asiática y a la necesidad de corregir déficit en cuenta corriente elevados. Indudablemente el comercio recíproco se verá sometido a tensiones en el proceso.

Asimismo, la convergencia de las más de dos decenas de acuerdos parciales exigirá soluciones imaginativas más bien pronto que tarde. ElALCA también podría dificultar la gestión, pero considerado sin apresuramiento y con madurez puede ser una presencia en el horizonte que estimule la tan necesaria convergencia dentro de América Latina.

Por otra parte, aumentará la demanda por mecanismos más eficaces de solución de controversias y de armonización de las políticas macro-económicas. En efecto, en la medida que el comercio intrarregional acreciente su importancia, crecen la interdependencia de las economías y los peligros de contagio de los schocks. Surge así la necesidad de hacer esfuerzos de coordinación macro-económica que contribuyan a fortalecer el entorno para el desarrollo productivo con equidad. 


\section{Referencias}

Ricardo French-Davis

El comercio intra

latinoaméricano en los años

noventa y su base analítica.

CEPAL (1994), Regionalismo abierto en

América Latina y el Caribe, Naciones

Unidas, Santiago.

CEPAL (1998), Políticas para mejorar la inserción en la economía mundial,

CEPAL/Fondo de Cultura Económica, Santiago, segunda edición.

Corden, M. (1972), «Economies of Scale and Customs Union Theory», Journal of Political Economy, vol. 80, No 3, Chicago, mayo-junio.

Devlin, R. y R. Ffrench-Davis (1998), «Towards an Evaluation of Regional Integration in Latin America in the 1990s», en The World Economy, por aparecer.

Ffrench-Davis, R. (1999), Macroeconomía, comercio y finanzas: para reformar las reformas, McGraw-Hill, Santiago.

Ffrench-Davis, R. (1980), «Distorsiones del mercado y teoria de las uniones aduaneras», Integración Latinoamericana, No 44, Buenos Aires, marzo.

Winters, A. (1998), “Assessing Regional Integration Arrangements", International Trade Division, The World Bank, Washington, D.C. 